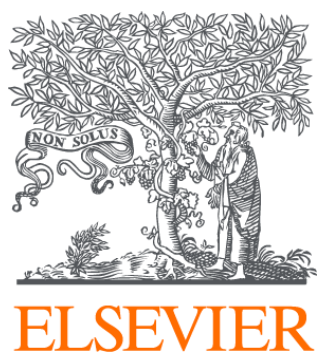

Since January 2020 Elsevier has created a COVID-19 resource centre with free information in English and Mandarin on the novel coronavirus COVID-

19. The COVID-19 resource centre is hosted on Elsevier Connect, the company's public news and information website.

Elsevier hereby grants permission to make all its COVID-19-related research that is available on the COVID-19 resource centre - including this research content - immediately available in PubMed Central and other publicly funded repositories, such as the WHO COVID database with rights for unrestricted research re-use and analyses in any form or by any means with acknowledgement of the original source. These permissions are granted for free by Elsevier for as long as the COVID-19 resource centre remains active. 


\title{
Sample sizes for surveillance of $S$. aureus transmission to monitor effectiveness and provide feedback on intraoperative infection control including for COVID-19
}

\author{
Franklin Dexter ${ }^{\mathrm{a}, *}$, Johannes Ledolter ${ }^{\mathrm{a}}$, Russell T. Wall ${ }^{\mathrm{b}}$, Subhradeep Datta ${ }^{\mathrm{c}}$, Randy W. Loftus ${ }^{\mathrm{a}}$ \\ ${ }^{\text {a }}$ University of Iowa \\ ${ }^{\mathrm{b}}$ MedStar Georgetown University Hospital \\ ${ }^{\mathrm{c}}$ Medical student 2022 class, Georgetown University
}

\section{A B S T R A C T}

Reductions in perioperative surgical site infections are obtained by a multifaceted approach including patient decolonization, hand hygiene, and hub disinfection, and environmental cleaning. Associated surveillance of $S$. aureus transmission quantifies the effectiveness of the basic measures to prevent the transmission to patients and clinicians of pathogenic bacteria and viruses, including Coronavirus Disease 2019 (COVID-19). To measure transmission, the observational units are pairs of successive surgical cases in the same operating room on the same day. We evaluated appropriate sample sizes and strategies for measuring transmission.

There was absence of serial correlation among observed counts of transmitted isolates within each of several periods (all $P \geq .18$ ). Similarly, observing transmission within or between cases of a pair did not increase the probability that the next sampled pair of cases also had observed transmission (all $P \geq .23$ ).

Most pairs of cases had no detected transmitted isolates. Also, although transmission (yes/no) was associated with surgical site infection $(P=.004)$, among cases with transmission, there was no detected dose response between counts of transmitted isolates and probability of infection $(P=.25)$.

The first of a fixed series of tests is to use the binomial test to compare the proportion of pairs of cases with $S$. aureus transmission to an acceptable threshold. An appropriate sample size for this screening is $\mathrm{N}=25$ pairs. If significant, more samples are obtained while additional measures are implemented to reduce transmission and infections. Subsequent sampling is done to evaluate effectiveness. The two independent binomial proportions are compared using Boschloo's exact test. The total sample size for the $1^{\text {st }}$ and $2^{\text {nd }}$ stage is $\mathrm{N}=100$ pairs.

Because $S$. aureus transmission is invisible without testing, when choosing what population(s) to screen for surveillance, another endpoint needs to be used (e.g., infections). Only 10/298 combinations of specialty and operating room were relatively common ( $\geq 1.0 \%$ of cases) and had expected incidence $\geq 0.20$ infections per 8 hours of sampled cases. The 10 combinations encompassed $\cong 17 \%$ of cases, showing the value of targeting surveillance of transmission to a few combinations of specialties and rooms.

In conclusion, we created a sampling protocol and appropriate sample sizes for using $S$. aureus transmission within and between pairs of successive cases in the same operating room, the purpose being to monitor the quality of prevention of intraoperative spread of pathogenic bacteria and viruses.

\section{Introduction}

Reductions in perioperative surgical site infection are obtained by a multifaceted approach including patient decolonization (viral antiseptic), hand hygiene, use of closed lumen intravenous systems and hub disinfection, and environmental cleaning facilitated by evidence-based surveillance feedback. ${ }^{[1,2]}$ This approach can be adapted to address transmission of Coronavirus Disease 2019 (COVID-19) to patients and clinicians. ${ }^{[3,4]}$

Monitoring of $S$. aureus transmission (e.g., from one patient to the next in an operating room) is done, in part, because perioperative $S$. aureus transmission is associated with surgical site infection. ${ }^{[1]}$ The efficacy of a bundle to reduce surgical site infections is greater when combined with feedback on transmission. ${ }^{[1]}$ Perioperative transmission has been linked to development of postoperative infections via single nucleotide variant analysis, ${ }^{[5-7]}$ including more pathogenic $S$. aureus strain characteristics owing to increased biofilm formation ${ }^{[5]}$ and desiccation tolerance ${ }^{[6]}$. Not only does $S$. aureus transmission involve patient skin, provider hand, and environmental reservoirs in operating rooms, ${ }^{[1,5-7]}$ the same applies to the epidemiology of perioperative transmission of Enterococcus, Klebsiella, Acinetobacter, Pseudomonas, and Enterobacter. ${ }^{[8-11]}$

Not surprisingly, the epidemiology of viral pathogen transmission, including but not limited to SARS-CoV-2, involves the same reservoirs, and thus the same hygiene measures are important to control viral spread. $^{[2,12,13]}$ Thus, monitoring of intraoperative $S$. aureus transmission not only serves as a measurement for the effectiveness of basic measures to prevent the operating room transmission of pathogenic

\footnotetext{
* Corresponding author.

E-mail address: franklin-dexter@uiowa.edu (F. Dexter).
} 
bacteria but also SARS-CoV-2..$^{[1,3,4]}$

To measure $S$. aureus transmission, the observational units are pairs of successive surgical cases in the same operating room on the same day. ${ }^{[1,14]}$ Routine sampling of pairs of cases is done by operating room nurses, surgical technologists, or anesthesia technicians. Each person doing sampling characteristically can sample two pairs of cases per day (e.g., one pair in the morning and another in the afternoon). ${ }^{[1,14]}$ Sampling is from a common targeted population, whether a facility with multiple services and operating rooms, a service at a facility among multiple operating rooms, or several operating rooms. More pairs of cases can be sampled in a day if cases are brief, because duration is not a significant covariate for transmission. ${ }^{[1,15]}$ Samples for culturing are taken at precisely chosen locations in operating rooms (e.g., anesthesia machine vaporizer or patient's nasopharynx) and epochs (e.g., before case starts and when finished). Transmission is established when the same $S$. aureus isolate is obtained from $\geq 2$ distinct, epidemiologically-related reservoirs within the pair of successive surgical cases. ${ }^{[1,14]}$

What is unknown is the minimum appropriate sample size of pairs of cases to evaluate if a hospital, surgical specialty, group of operating rooms, etc., has a sufficiently high incidence of transmission to warrant changes in infection control practices. To know whether perioperative infection control measures are effective, how many pairs of cases should be sampled? If that threshold incidence were exceeded, how many additional pairs should be sampled during and after implementation of an infection-reducing bundle, with feedback, to assess improvement? Finally, once bacterial (and viral) transmission has been mitigated, how often is sampling required for surveillance and feedback to detect new environmental contamination, with consequent risk of infection both to patients and healthcare workers?

\section{Previously unpublished data used for illustrations}

Data collection was approved by the Georgetown-Medstar Institutional Review Board.

S. aureus transmission was measured using OR PathTrac (RDB Bioinformatics, Coralville, Iowa) for 336 pairs of cases at the studied hospital over 235 days. Deidentified data are posted at https://FDshort. com/SampleSize2SeqTests. The specific dates are excluded deliberately. There are three data for each pair of cases: A) date in units of days from the starting date plus 1, ranging from 1-235; B) operating room numbered 1-24; and C) count of transmitted isolates, ranging from 0 10.

The sample size of 336 pairs of cases (Table 1) was not chosen to perform the current study. The start date of samples was chosen based on the hospital's objective to improve basic perioperative infection control measures. The last date of samples was early March 2020, by when there had been $>100$ cases in the USA of COVID-19. ${ }^{[16]}$ The authors performed analyses throughout March 2020, because we recognized that the data being collected could be used to address quickly the need for greater intraoperative infection control because of COVID$19{ }^{[3,4]}$ The hospital collected no additional samples in March because elective surgery was stopped because of the COVID-19 pandemic.

Interventions to reduce environmental contamination include capital equipment, and thus vary among operating rooms (e.g., anesthesia machines with greater ease of decontamination, ${ }^{[17]}$ specialized ventilation systems, ${ }^{[18,19]}$ germicidal lighting, ${ }^{[20]}$ door locks and electronic signage to prevent main and inner core doors from being open simultaneously, ${ }^{[21]}$ and rooms of different physical configurations ${ }^{[22]}$ ). Also, cases of different specialties are scheduled non-randomly into specific operating rooms. ${ }^{[15,23]}$ However, using the data (Table 1) for illustration, Kruskal-Wallis test (i.e., analysis of variance on ranks) for the counts of transmitted isolates did not differ significantly among the 24 rooms, $P=.32$ (STATA 16.0, College Station, TX). We created a fourth variable in the upload for readers, column D) transmitted isolate 0 versus $\geq 1$. The incidence of transmission did not differ significantly among rooms, Fisher exact test $P=.46$. Because the specific room was not a covariate, we performed subsequent work while pooling among rooms.

We divided the pairs of cases into quartiles of successive observations, creating the fifth variable in the uploaded worksheet, column E. Because the sample size was not a multiple of 4 , the pairs of cases in each of the periods were similar, but not identical (Table 1, range 83-86 pairs of cases). The unequal sample sizes among periods were selected to achieve absence of overlap of dates among the periods. The counts of transmitted isolates differed among periods, $P<.001$ using the KruskalWallis test. The percentage incidences of transmission also differed among periods, $P<.001$ using Fisher's exact test.

During the $1^{\text {st }}$ period, there were progressively increasing counts of transmitted $S$. aureus isolates and proportion of pairs of cases with transmission (Table 2). This is shown by the Kendall's $\tau_{\mathrm{b}}$ of the count data having positive association with date, and by logistic regression of the binary data having positive association with date. This increase in transmission during period 1 motivated the study hospital to improve patient decolonization, hand hygiene, use of closed lumen intravenous systems and hub disinfection, and environmental cleaning, supplemented by ongoing surveillance (e.g., to target the use of ultraviolet light [UV-C] for specific rooms ${ }^{[1,24]}$ ). For our purposes in using the data to evaluate sample sizes for surveillance of intraoperative transmission, the impact of the trend in period 1 was that the data from that period were omitted from subsequent analyses. The hospital did not revise the infection-reducing bundle during the periods with collected samples; during period 4, COVID-19 was minimally in its community.

\section{Statistical associations between sequential pairs of cases within periods}

Sample sizes for accurately estimating transmission within or between periods depend markedly on the serial correlation. ${ }^{[25]}$ When there is positive serial correlation, consecutive observations stay above average for some time, and vice-versa. Sample sizes need to be greater when there is positive serial correlation. The effect of serial correlation on sample size has been foundational to operating room management science and how those data need to be analyzed. ${ }^{[26-30]}$ For example, serial correlation is a reason why adjusted and raw utilization of operating room block time cannot be estimated accurately by surgeon. ${ }^{[2,27]}$ Serial correlation affects why cancellation rates and turnover times need to be analyzed using batches (bins) of two-weeks or longer. ${ }^{[28,30-32]}$

Another reason to know whether serial correlation is present is that

Table 1

Data from the studied hospital divided into quartiles by date.

\begin{tabular}{|c|c|c|c|c|c|}
\hline Period & $\mathrm{N}$ pairs of cases & Days from first date +1 & Mean (SD) transmitted isolates & Range transmitted isolates & $\%$ pairs of cases with transmission \\
\hline 1 & 84 & 1 to 88 & $0.45(1.36)$ & 0 to 8 & $14.29 \%$ \\
\hline 2 & 86 & 89 to 149 & $1.36(2.30)$ & 0 to 10 & $40.70 \%$ \\
\hline 3 & 83 & 150 to 194 & $0.76(1.86)$ & 0 to 10 & $20.48 \%$ \\
\hline 4 & 83 & 197 to 235 & $0.35(1.19)$ & 0 to 7 & $12.05 \%$ \\
\hline
\end{tabular}

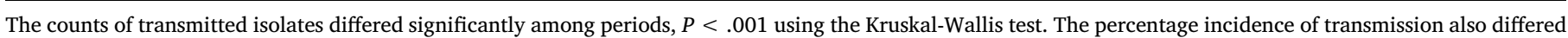
among periods, $P<.001$ using Fisher's exact test. 
Table 2

Trends and serial correlation within each of the 4 periods.

\begin{tabular}{|c|c|c|c|c|c|c|}
\hline Period & $\begin{array}{l}\mathrm{N} \text { pairs of } \\
\text { cases }\end{array}$ & $\begin{array}{l}\text { Kendall's } \tau_{\mathrm{b}} \text { transmitted } \\
\text { isolates }\end{array}$ & $\begin{array}{l}\text { Logistic regression transmitted or not, } \\
\text { odds ratio per each } 1 \text { day }\end{array}$ & $\begin{array}{l}\text { Runs test, transmitted } \\
\text { isolates, mean, Runs }\end{array}$ & $\begin{array}{l}\text { Runs test, transmitted } \\
\text { isolates, median }\end{array}$ & $\begin{array}{l}\text { Runs test, transmitted or } \\
\text { not }\end{array}$ \\
\hline 1 & 84 & $\begin{array}{l}0.23 \\
P=.009\end{array}$ & $\begin{array}{l}1.034, \\
P=.024\end{array}$ & $\begin{array}{l}21 \\
P=.97\end{array}$ & $\begin{array}{l}21 \\
P=.97\end{array}$ & $\begin{array}{l}21 \\
P=.97\end{array}$ \\
\hline 2 & 86 & $\begin{array}{l}0.01 \\
P=.91\end{array}$ & $\begin{array}{l}1.000 \\
P=.77\end{array}$ & $\begin{array}{l}41 \\
P=.18\end{array}$ & $\begin{array}{l}43 \\
P=.82\end{array}$ & $\begin{array}{l}43 \\
P=.82\end{array}$ \\
\hline 3 & 83 & $\begin{array}{l}-0.03 \\
P=.77\end{array}$ & $\begin{array}{l}0.993 \\
P=.71\end{array}$ & $\begin{array}{l}24, \\
P=.23\end{array}$ & $\begin{array}{l}24, \\
P=.23\end{array}$ & $\begin{array}{l}24 \\
P=.23\end{array}$ \\
\hline 4 & 83 & $\begin{array}{l}-0.11 \\
P=.21\end{array}$ & $\begin{array}{l}0.939 \\
P=.17\end{array}$ & $\begin{array}{l}19 \\
P=.63\end{array}$ & $\begin{array}{l}19 \\
P=.63\end{array}$ & $\begin{array}{l}19 \\
P=.63\end{array}$ \\
\hline
\end{tabular}

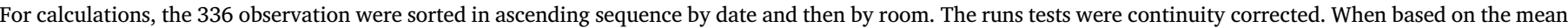

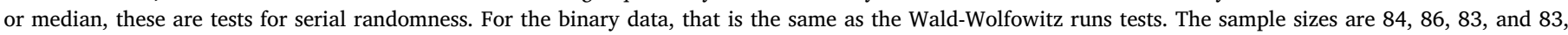

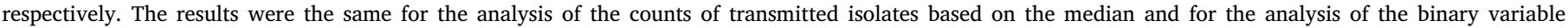

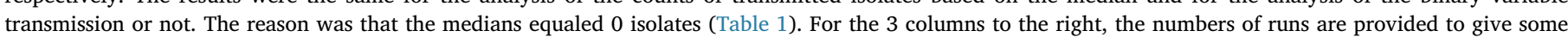

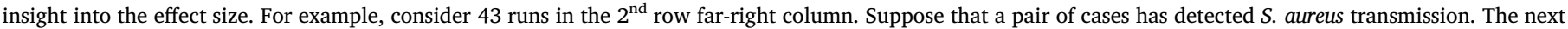

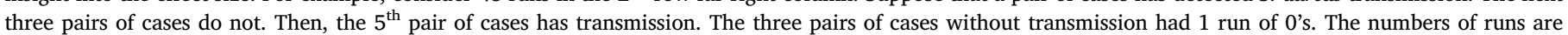
sequences of all 0 's or all 1's.

positive serial correlation could be an advantage when selecting pairs of cases for sampling. ${ }^{[33]}$ For example, suppose that a hospital may implement an infection control bundle and feedback for two populations, plastic surgery and gynecological oncology. If there were substantial serial correlation, then if a pair of successive cases of plastic surgery had detected transmission, the next pair of cases sampled likely should be plastic surgery. ${ }^{[33]}$ There also would be an advantage to having the $S$. aureus results available by early the next day for purposes of selecting pairs of cases for surveillance. However, if there was no serial correlation, results need not (and should not) influence sampling. ${ }^{[15]}$

When a pair of cases for which sampling was done at the studied hospital had counts of transmitted isolates that were above average for the period, with the average estimated using the sample mean (Table 1), was there increased chance that the next sampled pair of cases also had transmitted isolates that were above average? That was not so, $P=.18, P=.23$, and $P=.63$ among periods 2,3 , and 4 , respectively (Table 2). Similarly, we asked whether observing transmission within or between cases of a pair ${ }^{[1,14]}$ increased the probability that the next sampled pair of cases also had observed transmission. That too was not so, $P=.82, P=.23$, and $P=.63$, respectively (Table 2). Finally, there was not significant serial correlation detected by the runs test by date (Table 3). These results imply that there is no need to adjust the sample size calculations shown below for serial correlation.

\section{Sample sizes are based on proportion of pairs of cases with $S$. aureustransmission}

Three facts indicate that the endpoint for designing sampling should be the presence versus absence of transmission (i.e., 0 versus $\geq 1$ transmitted isolate).

First, most (i.e., greater than half) of the pairs of cases had no detected transmitted isolates (Table 1).

Second, the counts of transmitted isolates depend on the numbers of sampling time points and locations. For example, in the randomized study of infection control bundle with feedback, there were 33 samples per pair of cases, preoperative, intraoperative, and postoperative. ${ }^{[1]}$ In

Table 3

Tests of lag 1 serial correlation within each of the periods using presence or absence of $S$. aureus transmission among all pairs of cases on the same day.

\begin{tabular}{llc}
\hline Period & N days & Runs, P-value \\
\hline 1 & 53 & $19, P=.95$ \\
2 & 41 & $25, P=.67$ \\
3 & 30 & $15, P=.39$ \\
4 & 25 & $11, P=.47$ \\
\hline
\end{tabular}

contrast, an ongoing prospective observational study of bactericidal intraoperative lighting has 22 samples per pair of cases, all intraoperative. ${ }^{[20,34]}$ Different hospitals will choose from among sampling time points and locations based on presumptive information. Therefore, the means of the counts (Table 1 column 4) are influenced by the skewness of the data and may differ among hospitals based on how many samples are done for each pair of cases. In other words, the recommended sample size based on the means may not be generalizable among hospitals.

Third, in the randomized study, surgeons were assigned at random to a group with usual infection control or to another group with an infection control bundle and feedback on $S$. aureus perioperative transmission. ${ }^{[1]}$ Transmission, the primary study endpoint, was associated with surgical site infection; $11.0 \%(8 / 73)$ of patients with $S$. aureus transmission detection had infection versus $1.8 \%(3 / 163)$ without transmission detection, risk ratio $5.95,95 \%$ confidence interval 1.63-21.80, $P=.004$. $^{[1]}$ We evaluated for the current study whether transmission of more isolates was associated with greater risk for infection. ${ }^{[1]}$ Among the 11 patients with surgical site infections, ${ }^{[1]}$ the counts of transmitted isolates $\times$ patients were $8 \times 1,7 \times 1,3 \times 4$, and $1 \times 2$. In comparison, among all 73 patients with transmitted isolates, the distribution of counts of transmitted isolates were $10 \times 1,8 \times 1$, $7 \times 4,6 \times 3,5 \times 7,4 \times 8,3 \times 8,2 \times 16$, and $1 \times 25$. Using the Kolmogorov-Smirnov two-sample test to compare the distributions of non-zero counts between groups, $N=11$ and $N=73$, respectively, the exact two-sided $P=.25$. Therefore, the distributions did not differ significantly.

Based on the preceding three observations, we subsequently neglect the counts for purposes of inference, and use the binary, presence or absence of transmission.

\section{Adjustment of type I error rate for the 2 sequential tests}

What we have determined to this point is that two statistical tests will be performed in a fixed sequence (Table 4). First, the binomial proportion of pairs of cases with $S$. aureus transmission will be estimated. The null hypothesis tested using the binomial test will be that the incidence does not differ from an acceptable threshold. If $\mathrm{P} \geq \alpha$ (e.g., with $\alpha=.05$ ), sampling ceases because it would be more useful to target other populations (e.g., operating rooms). If $\mathrm{P}<\alpha$ for the onesided alternative that the incidence of transmission is greater than threshold, more sampling commences. During the weeks spent preparing to implement additional measures to prevent transmission and infections, sampling continues if, as shown below, more samples are needed at baseline to evaluate reductions over time. After intervention starts, sampling is done for a similar number of pairs of cases to 
Table 4

Implementation steps for surveillance of $S$. aureus transmission to monitor effectiveness and provide feedback on intraoperative infection control.

\begin{tabular}{|c|c|}
\hline Step & Protocols \\
\hline 1 & $\begin{array}{l}\text { Identify for each hospital what populations would be evaluated } \\
\text { Apply the principles in Table } 5 \text { and its legend to choose combinations of specialty and operating room }\end{array}$ \\
\hline 2 & $\begin{array}{l}\text { For each population selected from Step 1, sample from } 25 \text { successive pairs of cases } \\
\text { For large initial incidences of transmission, } 15 \text { pairs of cases may be enough }\end{array}$ \\
\hline 3 & $\begin{array}{l}\text { For each population from Step } 2 \text { with incidences of transmission exceeding threshold by the binomial test, perform additional sampling while implementing enhanced } \\
\text { infection control } \\
\text { Sampling would be } 75 \text { additional pairs of cases, but for large initial incidences } 43 \text { additional pairs of cases may be enough }\end{array}$ \\
\hline 4 & $\begin{array}{l}\text { For each population from Step } 3 \text { with significant decline in transmission by Boschloo's exact test, monitor sustained performance by sampling from 1-2 (average 1.5) pairs } \\
\text { of cases per workday } \\
\text { Using Bernoulli Cumulative Sum control charts (CUSUM), expect to detect increase comparable to Table } 1 \text { within } 3 \text { months, while keeping the average number of } \\
\text { observations to false signal at } 15 \text { months, as shown in the uploaded file at https://FDshort.com/SampleSize2SeqTests }\end{array}$ \\
\hline
\end{tabular}

estimate the achieved lower incidence of $S$. aureus transmission. The null hypothesis tested by comparing the two independent binomial proportions would be no difference in the proportions of pairs of cases with transmission. The alternative hypothesis would be one-sided, a reduction in incidence. (Use of infection control bundles may be ineffective, but they do not result in greater transmission.)

What we consider in the current section is how to adjust the selected Type I error rates for each of the 2 sequential tests to achieve an overall $\alpha=.05$. This is straightforward because the 2 hypotheses are tested in a fixed sequence, and if the finding for the first hypothesis were $P \geq \alpha$, there would be no need for consideration for the second hypothesis. To achieve an overall family-wise Type I error rate of $\alpha$ under such a model, each of the sequential tests is performed using the original $\alpha$ level. ${ }^{[35-37]}$ In other words, no adjustment should be made.

\section{Sample size estimation using the observational data from the study hospital}

As summarized in the preceding section, the first of the two hypotheses tests whether the proportion of pairs of cases with incidence of transmission of $S$. aureus significantly exceeds a low threshold. For that threshold we use $12.05 \%$, from Table 1 period 4 . We plan for $80 \%$ statistical power to detect a greater incidence of transmission at baseline, using the largest observed incidence, $40.70 \%$ from Table 1 Period 2,35 of 86 pairs. Using $\alpha=.05$, the exact sample size for the one-sided binomial test would be $N=15$ pairs of cases. Calculations were performed using StatXact-12.0 (Cytel, Inc., Cambridge, MA).

The null hypothesis for the second test is no difference between the two groups, before and after. We use the two-group one-sided Boschloo's exact test for the difference of independent proportions (StatXact-12.0). Comparing $40.7 \%$ with $12.05 \%$, again with $\alpha=.05$, the exact sample size would be $N=29$ pairs of cases in each of the two groups. Therefore, 14 pairs of cases would be collected while the infection control bundle is being planned and implemented progressively, where $14=29-15$ already collected. There would be 29 pairs of cases sampled after use of greater infection control. The total sample size would be $\cong 58$ pairs of cases.

The preceding sample size is based on use of Boschloo's test (Table 4). Because we are performing one-sided tests, three common alternatives (Fisher's exact test, Pearson chi-squared test, and the likelihood ratio test) give identical P-values. ${ }^{[38]}$ Therefore, we consider the statistical power of Fisher's exact test. Boschloo's test has greater statistical power than Fisher's exact test under all combinations of $\alpha$, total sample size, and distribution of cases between groups. ${ }^{[39]}$ For example, whereas Boschloo's test would require $N=29$ per group (above), the sample size for Fisher's exact test would be 34 per group (StatXact12.0). Fisher's exact test is not always available as a one-sided test, and, if so, the sample size would be 41 per group. Importantly, just like
Fisher's exact test, Boschloo's test does not have Type I error rates exceeding nominal levels under our conditions. ${ }^{[39]}$ For example, for twosided tests with $\alpha=.05$, and $\mathrm{N}=50$ in each of the two groups, and proportions of $10.0 \%$ or $25.0 \%$ in each of the two groups, for $3.2 \%$ or $4.1 \%$ of simulations the null hypothesis was rejected, neither exceeding the nominal incidence of 5.0\%. ${ }^{[39]}$ Therefore, the use of Boschloo's test for surveillance of $S$. aureus transmission is reasonable.

Bernoulli Cumulative Sum (CUSUM) control chart for sustained monitoring is shown in the uploaded file (Table 4). ${ }^{[40]}$

\section{Example based on incidences from prior randomized trial}

The preceding incidences were not obtained as part of a formally described and followed protocol. Therefore, although the incidences were estimated accurately, they may not be generalizable. To address this potential limitation, we repeated our sample size calculations using estimates of incidence from the recently published randomized trial. ${ }^{[1]}$

In the trial, surgeons were assigned either to a group with usual infection control or to another group with an infection control bundle for 4 months followed by bundle with feedback on $S$. aureus perioperative transmission for 8 months. ${ }^{[1]}$ At 12 months, among the patients of the surgeons randomized to usual practice, 50 of 130 pairs of cases had $S$. aureus transmission. That was an incidence of $38.5 \%$, versus $40.70 \%$ from Table 1 . In the treatment (bundle and feedback) group, 11 of 68 pairs of cases had transmission. That was an incidence of $16.2 \%$, versus $12.05 \%$ from Table 1 .

The first of the two hypotheses tests would be the one group onesided binomial test. Comparing $38.5 \%$ as the baseline with a threshold of $16.2 \%$, using $80 \%$ statistical power and $\alpha=.05$, the exact sample size needed would be $N=25$ pairs of cases. For facilities seeking greater confidence in the quality of infection control, but at the cost of more samples, using $90 \%$ statistical power the necessary sample size would be $N=34$ pairs of cases.

The second of the two hypotheses, tested only if the first were statistically significant, would be the one-sided Boschloo exact test for the difference of the independent proportions. Comparing 38.5\% with $16.2 \%$, again using $80 \%$ statistical power and $\alpha=.05$, the exact sample size needed would be 50 in each of the two groups. Therefore, 25 pairs of cases would be collected while the infection control bundle is being planned and implemented, where $25=50$ for the test of the second hypothesis minus 25 from the test of the first hypothesis. There would be 50 pairs of cases sampled after use is being done consistently. The total sample size would be 100 pairs of cases. For facilities wanting to assure more reliably that decrease in transmission has occurred, using $\alpha=.01$, the total sample size would be 162 pairs of cases.

The University of Iowa's plan is to rely on the need for 25 pairs of cases for screening, and 75 additional pairs for each studied population (Table 4). 


\section{Defining the population: adopt a stratified sampling strategy}

Because $S$. aureus transmission is invisible without testing, when choosing what population(s) to screen for surveillance, another endpoint needs to be used. For example, at the University of Iowa, currently during the COVID-19 pandemic, process measures are being reported daily, including use of patient decolonization (viral antisepsis) and patient initial phase I post-anesthesia care unit recovery and multimodal cleaning after each higher risk procedure or when the procedure is sufficiently urgent that it was started before the results of testing for SARS-CoV-2 were complete. ${ }^{[1-4,12,13,24]}$ We provide an example of defining the population for sampling by using patient outcomes (i.e., infection) data from 4 studies of closed lumen intravenous systems and hand decontamination. ${ }^{[41-44]}$ (These were deidentified data that we had available, and quickly given that the current study was performed acutely when the COVID-19 pandemic spread to the USA). The overall incidence of hospital acquired infection was 7.5\%, 294 infections among the 3936 cases (i.e., rows in the uploaded file). Associations known from previous studies supported validity to this use of the data. Specifically, increases in anesthesia duration were associated with greater incidence of infection $(P<.0001$ by Kendall's $\tau$ and logistic regression). ${ }^{[23,45-47]}$ In addition, by Kruskal-Wallis tests, the incidence differed among the 11 specialties $(P=.0001)^{[23,45-47]}$ and among the 86 different operating rooms $(P=.0001) .{ }^{[23]}$ For example, the incidences of infection were $15.5 \%$ for urology and $11.5 \%$ for gynecology versus $4.7 \%$ for otolaryngology and $5.0 \%$ for orthopedic surgery. Among the 24 of 86 rooms each with at least $1.0 \%$ of cases, the two largest incidences of infection were $14.1 \%$ and $14.0 \%$, and the lowest observed incidences were $3.1 \%$ and $3.2 \%$.

We examined the benefit of limiting the population sampled to a few combinations of specialty and room (Table 4). ${ }^{[15], 1}$ Operating room matters not only because environmental contamination affects the room, and interventions to reduce transmission include capital equipment installed in specific rooms, ${ }^{[17-19,20-22]}$ but because sampling of $S$. aureus transmission is for successive cases in the same room and day. Specialty matters because transmission differs among specialties, the incidences of infection differ among specialties, interventions to reduce surgical site infections have contributions differing among specialties, and the distribution of cases of different specialties differ among rooms due to case scheduling. ${ }^{[6,7,14,15,23]}$ For example, even though a breast surgery case may follow an orthopedic case, ${ }^{[43,44]}$ the pairing is sufficiently uncommon, and patient care sufficiently different, as to make such pairing non-insightful. Because $S$. aureus transmission does not appear to be influenced by duration, ${ }^{[1,6,7,14]}$ there is more opportunity by choosing pairs of cases from specialty $\times$ rooms with more expected infections per hour ${ }^{[15]}$. Among the 298 combinations of specialty and room, there were only 10 that were both relatively common, $\geq 1.0 \%$ of cases, and expected to have $\geq 0.20$ infections per 8 hours of sampled cases (Table 5 ). The 10 combinations encompassed $\cong 17 \%$ of cases, the population(s) to be targeted for surveillance of transmission. If sampling will be done, pooled, with several combinations of specialty and room, then stratified sampling would ideally be done to achieve balance before versus after implementation of enhanced infection control.

\footnotetext{
${ }^{1}$ As written in the Introduction, from our previous studies, more pairs of cases can be sampled in a day if cases are brief, because duration is not a significant covariate for transmission. ${ }^{1,15}$ For the observational data (Table 1), case durations of the pairs were available for the first 209 pairs by date. Using the Wilcoxon-Mann-Whitney test, there was the same finding of absence of association between duration and transmission $(P=.91)$. Consequently, having chosen the specialty and room combinations to study, and knowing the total sample sizes of pairs of cases to obtain, sampling strategies should include the daily, deliberate, selection of the briefest pairs of cases. ${ }^{15}$
}

\section{Discussion}

Monitoring of $S$. aureus transmission is done, in part, because it serves as a measurement for the effectiveness of basic measures to prevent the transmission of pathogenic bacteria and viruses. The efficacy of an infection control bundle alone is greater when combined with feedback on transmission. ${ }^{[1]}$ We determined the statistical design for initiating surveillance. As listed pointwise in Table 4, first, sampling would be done from one or a few different combinations of specialty and room. Second, plan to monitor the incidence of $S$. aureus transmission within and between successive cases. Perform 2 tests in fixed sequence. Sample from 25 pairs of cases (from the randomized trial [Section 7], 15 based on the observational data [Section 6]). Use the binomial test to evaluate if significantly high incidence of transmission. Third, if so, continue surveillance while initiating interventions, obtaining an extra 25 (or 14) pairs of cases. Evaluate effectiveness of modified patient decolonization (viral antiseptic) ${ }^{[2]}$ hand hygiene, use of closed lumen intravenous systems and hub disinfection, and environmental cleaning using 50 (or 29) pairs of cases, applying Boschloo's exact test. The larger sample sizes (i.e., the total of 50 pairs of cases) are those obtained based on the recently completed randomized trial showing reduced $S$. aureus transmission and surgical site infections. ${ }^{[1]}$ Fourth, follow-up monitoring can be done using Bernoulli CUSUM control charts.

The surveillance of $S$. aureus transmission as studied in this paper applies to feedback to a hospital (e.g., Tables 1-3), surgical specialty (e.g., Table 4), and/or study sponsor with capital equipment installed in individual operating rooms (e.g., as described in Reference 15). Feedback would not be by individual (e.g., surgeon), because perioperative infection bundles are multidisciplinary (e.g., include patient decolonization done before operating room entrance and environmental cleaning by housekeepers). The results of the current study show also that sample sizes would be insufficient. For example, we consider the futility of reporting the incidence of pairs of cases with transmission by surgeon (or proceduralist). Among the surgeons in the randomized trial, $0 / 32$ had 25 pairs of cases over 6 months and only $2 / 32$ had at least 15 pairs each 6-months. ${ }^{[1]}$ At the outpatient surgery center of a large teaching hospital in Pennsylvania, only 2/65 surgeons had enough workload to fill an operating room for 8 hours every week. ${ }^{[48]}$ At the hospital's main surgical suite, only $28 \%$ of the surgeons (59/211) had enough workload to fill 1 room every week. ${ }^{[48]}$ A large teaching hospital in New York had at most 1 pair of cases per month for 36/45 surgeons. ${ }^{[49]}$ Statewide among Iowa's 117 hospitals, 54\% (SE 2\%) of the surgeon-days with at least 1 outpatient case had only one case (i.e., there would be no pairs of cases to sample by surgeon). ${ }^{[50]}$ Statewide among Florida's 147 facilities with anesthesiologist pain medicine physicians performing spinal neuromodulation procedures, 98\% (SE $1 \%$ ) of the proceduralist-facility weeks had zero or one case. ${ }^{[51]}$ Furthermore, we do not think that feedback to individual surgeons, anesthesiologists, etc., would be necessary. During the era of COVID-19, infection control processes protect the healthcare worker and his/her colleagues, not only the patients.

A limitation of our study is that the data did not include transmission measured using whole cell genome analysis. ${ }^{[7]}$ Genomic analysis permits characterization of reservoirs of origin leading to infection and identification of reservoirs such as operating room environments or provider hands that infect repeatedly over days and weeks. Such feedback, different than examined in the current study, is useful when a hospital is faced with especially pathogenic pathogens, such as strong biofilm forming and/or desiccation tolerating $S$. aureus strains or ESKAPE pathogens. ${ }^{[6-8,14]}$ Furthermore, a hospital may want to examine the particular path for transmission of pathogens commonly linked to infections in their organization. Such transmission stories (i.e., essentially quality improvement case reports within the organization), require analysis of data by individual patient. The surveillance approach presented in the current paper represents only one option for use of 
Table 5

Example of value of selecting combinations of specialty and operating room for sampling based on expected infections per case hour

\begin{tabular}{|c|c|c|c|c|c|c|c|}
\hline Specialty & Room & Cases & Cumulative \% Cases & Infections (\%) & Mean Hours per Case & Infections per 8 Hours & 8-Hour Workdays for 25 Pairs of Cases \\
\hline Gynecology & 85 & 71 & $2 \%$ & $11.3 \%$ & 2.6 & 0.35 & 16.3 \\
\hline Otolaryngology & 48 & 43 & $3 \%$ & $11.6 \%$ & 2.8 & 0.33 & 17.7 \\
\hline Orthopedics & 63 & 46 & $4 \%$ & $15.2 \%$ & 3.7 & 0.33 & 23.1 \\
\hline Plastics & 56 & 80 & $6 \%$ & $10.0 \%$ & 2.7 & 0.30 & 16.9 \\
\hline Vascular & 73 & 62 & $8 \%$ & $11.3 \%$ & 3.3 & 0.28 & 20.5 \\
\hline Thoracic & 75 & 44 & $9 \%$ & $13.6 \%$ & 4.0 & 0.27 & 24.8 \\
\hline Plastics & 72 & 45 & $10 \%$ & $8.9 \%$ & 2.8 & 0.25 & 17.5 \\
\hline Orthopedics & 69 & 132 & $13 \%$ & $6.8 \%$ & 2.4 & 0.23 & 14.9 \\
\hline Orthopedics & 60 & 97 & $16 \%$ & $6.2 \%$ & 2.3 & 0.21 & 14.5 \\
\hline Vascular & 74 & 67 & $17 \%$ & $7.5 \%$ & 3.0 & 0.20 & 18.5 \\
\hline
\end{tabular}

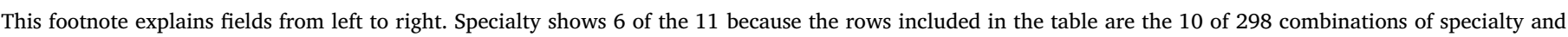

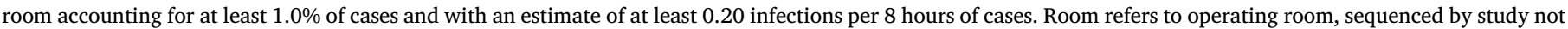

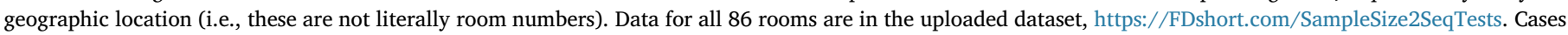

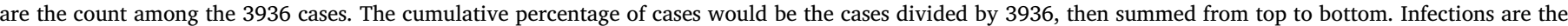

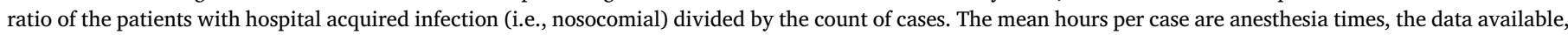

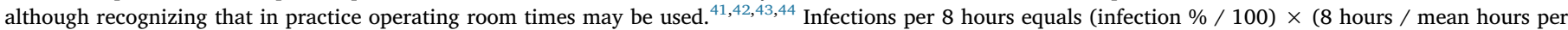

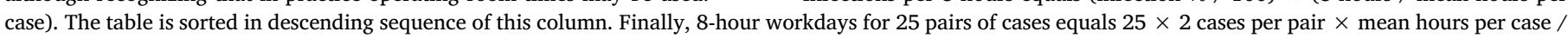
8 hours.

surveillance for improvement in perioperative infection control practices. The approach in the current paper is that applicable to monitoring of $S$. aureus transmission as a quantitative measure for infection control quality (e.g., appropriate for the COVID-19 crisis). ${ }^{[3,4]}$

Our study examined statistical designs for initiating and monitoring $S$. aureus transmission within and among proven reservoirs as a marker of behavioral performance at applying all facets of an infection-control bundle. ${ }^{[5-7,41,43]}$ Preventing environmental contamination is important not only because it endangers patients but also healthcare workers. For example, hyper-transmissible desiccation resistant $S$. aureus was isolated at the end of cases from anesthesiology residents' hands, certified registered nurse anesthetists' hands, and anesthesia machines' dials and valves. ${ }^{[6]}$ Similarly, viable SARS-CoV-1 and SARS-CoV-2 was isolated days later after experimental placement from plastic and stainless steel surfaces, and in hospital swabbing studies SARS-CoV-1 was found to have been transmitted to nursing stations' computers, telephones, doorknobs, and tables. ${ }^{[52-55]}$ SARS-CoV-2 was detected on water machines, elevator buttons, telephones, computer mice, and keyboards (i.e., environmental surfaces - no air samples had detectable virus). ${ }^{\left[{ }^{[5]}\right.}$ In a previous study we addressed operating room management strategies to reduce personnel risk from COVID-19 (e.g., preoperatively testing all patients for SARS-CoV-2 before elective surgery and limiting lower airway aerosol producing procedures to a few designated rooms). ${ }^{[4]}$ Others have addressed the disinfection of personal protective equipment. $^{[57-59]}$

Finally, our results are limited by the data used, because they were not collected for purposes of the study. However, because of the COVID19 pandemic, the University of Iowa initiated rapid dissemination of the multifaceted approach ${ }^{[1]}$ to reduce intraoperative bacterial and viral contamination, and plans to use Bernoulli CUSUM to monitor for group level feedback of sustainability. ${ }^{[40]}$ We needed to know appropriate sample sizes, inferential testing, and basis for selecting pairs of cases to sample. Yet, implementation of intraoperative infection control bundles and feedback are not literally two periods, as we modeled, they are a time series. The use of segmented regression in the logit scale, for the binary variable of transmission or not, seems an intuitively better choice. However, from the available data, we not only have insufficient sample size to develop such a model for statistical power analyses, we lack the necessary data explaining why specific pairs of cases were sampled at the studied hospital. Because preventing intraoperative environmental contamination from COVID-19 is essential for the acute crisis, we hope others use our results, collect more data, and can make comparisons with our uploaded data.

\section{Funding}

This study was funded in part by the Anesthesia Patient Safety Foundation and by the Department of Anesthesia, University of Iowa.

\section{CRediT authorship contribution statement}

Franklin Dexter: Conceptualization, Methodology, Software, Validation, Formal analysis, Resources, Data curation, Writing - original draft, Writing - review \& editing. Johannes Ledolter: Formal analysis, Writing - original draft, Writing - review \& editing. Russell T. Wall: Resources, Writing - review \& editing. Subhradeep Datta: Investigation, Writing - review \& editing. Randy W. Loftus: Conceptualization, Writing - original draft, Writing - review \& editing.

\section{Declaration of Competing Interest}

The Division of Management Consulting of the University of Iowa's Department of Anesthesia provides consultations to hospitals. Dr. Dexter receives no funds personally other than his salary and allowable expense reimbursements from the University of Iowa and has tenure with no incentive program. His family and he have no financial holdings in any company related to his work, other than indirectly through mutual funds for retirement. Income from the Division's consulting work is used to fund Division research. A list of all the Division's consults is available at FranklinDexter.net/Contact_Info.htm. Drs. Ledolter, Wall, and Datta have nothing to disclose. Dr. Loftus reports research funding from Sage Medical Inc., BBraun, Draeger, and Kenall, has one or more patents pending, and is a partner of RDB Bioinformatics, LLC, and 1055 N 115th St \#301, Omaha, NE 68154, a company that owns OR PathTrac, and has spoken at educational meetings sponsored by Kenall and BBraun. Medstar Health purchased the RDB Bioinformatics PathTrac system for measuring bacterial transmission.

\section{References}

1. Loftus RWs, Dexter F, Goodheart MJ, McDonald M, Keech K, Noiseux N, Pugely A, Sharp W, Sharafuddin M, Lawrence WT, Fisher M, McGonagill P, Shanklin J, Skeete D, Tracy C, Erickson B, Granchi T, Evans L, Schmidt E, Godding J, Brenneke R, Persons D, Herber A, Yeager M, Hadder B, Brown J. Improving basic preventive measures in the perioperative arena to reduce $S$. aureus transmission and surgical site infections, a randomized trial. JAMA Network Open. 2020;3:e201934.

2. Loftus RW, Dexter F, Parra MC, Brown JR. Importance of oral and nasal decontamination for patients undergoing anesthetics during the COVID-19 era. Anesth Analg. 2020. https://doi.org/10.1213/ane.0000000000004854.

3. Dexter F, Parra MC, Brown JR. Loftus RW. Perioperative COVID-19 defense: an 
evidence-based approach for optimization of infection control and operating room management. Anesth Analg. 2020. https://doi.org/10.1213/ANE. 0000000000004829.

4. Dexter F, Elhakim M, Loftus RW, Seering MS, Epstein RH. Strategies for daily operating room management of ambulatory surgery centers following resolution of the acute phase of the COVID-19 pandemic. J Clin Anesth. 2020;64:109854.

5. Loftus RW, Dexter F, Robinson A. Methicillin-resistant S. aureus has greater risk of transmission in the operating room than methicillin-sensitive S. aureus. Am J Infect Control. 2018;46:520-525.

6. Loftus RW, Dexter F, Robinson ADM, Horswill AR. Desiccation tolerance is associated with Staphylococcus aureus hyper transmissibility, resistance, and infection development in the operating room. J Hosp Infect. 2018;100:299-308.

7. Loftus RW, Dexter F, Robinson A. High-risk S. aureus transmission in the operating room: a call for widespread improvements in perioperative hand hygiene and patient decolonization practices. Am J Infect Control. 2018;46:1134-1141.

8. Hadder B, Patel HM, Loftus RW. Dynamics of intraoperative Klebsiella, Acinetobacter, Pseudomonas, and Enterobacter transmission. Am J Infect Control 2018;46:526-532.

9. Loftus RW, Koff MD, Brown JR, Patel HM, Jensen JT Reddy S, Ruoff KL, Heard SO, Yeager MP, Dodds TM. The dynamics of Enterococcus transmission from bacterial reservoirs commonly encountered by anesthesia providers. Anesth Analg. 2015;120:827-836.

10. Loftus RW, Koff MD, Brown JR, Patel HM, Jensen JT Reddy S, Ruoff KL, Heard SO, Dodds TP, Yeager MP. Transmission dynamics of gram negative bacterial pathogens in the anesthesia work area. Anesth Analg. 2015;120:819-826.

11. Loftus RW, Brown JR, Koff MD, Reddy S, Heard SO, Patel HM, Fernandez PG, Beach ML, Corwin HL, Jensen JT, Kispert D, Huysman B, Dodds TM, Ruoff KL, Yeager MP. Multiple reservoirs contribute to intraoperative bacterial transmission. Anesth Analg. 2012;114:1236-1248.

12. Eggers M, Eickmann M, Zorn J. Rapid and effective virucidal activity of povidoneiodine products against Middle East Respiratory Syndrome Coronavirus (MERS-CoV) and Modified Vaccinia Virus Ankara (MVA). Infect Dis Ther. 2015;4:491-501.

13. Eggers M. Infectious disease management and control with povidone iodine. Infect Dis Ther. 2019;8:581-593.

14. Robinson A, Dexter F, Renkor V, Reddy S, Loftus R. Operating room PathTrac analysis of current intraoperative S. aureus transmission dynamics. Am J Infect Control. 2019;47:1240-1247.

15. Dexter F, Epstein RH, Gostine AL, Penning DH, Loftus RW. Benefit of systematic selection of pairs of cases matched by surgical specialty for surveillance of bacterial transmission in operating rooms. Am J Infect Control. 2020. https://doi.org/10.1016/ j.ajic.2019.09.025.

16. Centers for Disease Control and Prevention, Coronavirus Disease 2019 (COVID-19). Cases in U.S.https://www.cdc.gov/coronavirus/2019-ncov/cases-updates/cases-inus.html. Accessed March 26, 2020.

17. Dexter F, Hermann J, Godding JD, Hadder B, Loftus RW. Assessment of anesthesia machine redesign on cleaning of the anesthesia machine using surface disinfection wipes. Am J Infect Control. 2020. https://doi.org/10.1016/j.ajic.2019.09.016.

18. Al-Waked R. Effect of ventilation strategies on infection control inside operating theatres. Eng Appl Comp Fluid. 2010;4:1-16.

19. Thomas AM, Simmons MJ. The effectiveness of ultra-clean air operating theatres in the prevention of deep infection in joint arthroplasty surgery. Bone Joint J. 2018;100$\mathrm{B}(10): 1264-1269$

20. Murrell LJ, Hamilton EK, Johnson HB, Spencer M. Influence of a visible-light continuous environmental disinfection system on microbial contamination and surgical site infections in an orthopedic operating room. Am J Infect Control. 2019;47:804-810.

21. Weiser MC, Shemesh S, Chen DD, Bronson MJ, Moucha CS. The effect of door opening on positive pressure and airflow in operating rooms. J Am Acad Orthop Surg. 2018;26:e105-e113.

22. McNeer RR, Bennett CL, Horn DB, Dudaryk R. Factors affecting acoustics and speech intelligibility in the operating room: size matters. Anesth Analg. 2017;124:1978-1985.

23. Dexter F, Ledolter J, Epstein RH, Loftus RW. Importance of operating room case scheduling on analyses of observed reductions in surgical site infections from the purchase and installation of capital equipment in operating rooms. Am J Infect Control. 2020;48:566-572

24. Bedell K, Buchaklian AH, Perlman S. Efficacy of an automated multiple emitter whole-room Ultraviolet-C disinfection system against coronaviruses MHV and MERSCoV. Infect Control Hosp Epidemiol. 2016;37:598-599.

25. Law AM, Kelton WD. Simulation Modeling and Analysis. 2nd ed. New York: McGrawHill, 1991:551-3.

26. Dexter F, Macario A, Traub RD, Hopwood M, Lubarsky DA. An operating room scheduling strategy to maximize the use of operating room block time: Computer simulation of patient scheduling and survey of patients' preferences for surgical waiting time. Anesth Analg. 1999;89:7-20.

27. Dexter F, Traub RD, Macario A, Lubarsky DA. Operating room utilization alone is not an accurate metric for the allocation of operating room block time to individual surgeons with low caseloads. Anesthesiology. 2003;98:1243-1249.

28. Dexter F, Marcon E, Epstein RH, Ledolter J. Validation of statistical methods to compare cancellation rates on the day of surgery. Anesth Analg. 2005;101:465-473.

29. Dexter F, Epstein RH, Marcon E, Ledolter J. Estimating the incidence of prolonged turnover times and delays by time of day. Anesthesiology. 2005;102:1242-1248.

30. Austin TM, Lam HV, Shin NS, Daily BJ, Dunn PF, Sandberg WS. Elective change of surgeon during the OR day has an operationally negligible impact on turnover time. $J$ Clin Anesth. 2014;26:343-349.
31. Ryckman FC, Yelton PA, Anneken AM, Kiessling PE, Schoettker PJ, Kotagal UR. Redesigning intensive care unit flow using variability management to improve access and safety. Jt Comm J Qual Patient Saf. 2009;35:535-543.

32. Dexter F, Maxbauer T, Stout C, Archbold L, Epstein RH. Relative influence on total cancelled operating room time from patients who are inpatients or outpatients preoperatively. Anesth Analg. 2014;118:1072-1080.

33. Gutiérrez Sandra, Krumke SO, Megow N, Vredeveid T. How to whack moles. Theor Comput Sci. 2006;361:329-341. https://doi.org/10.1016/j.tcs.2006.05.017.

34. Accessed. March 26, 2020https://clinicaltrials.gov/ct2/show/NCT04264715.

35. Bauer P. Multiple testing in clinical trials. Stat Med. 1991;10:871.

36. Bauer P, Röhmel J, Maurer W, Hothorn L. Testing strategies in multi-dose experiments including active control. Stat Med. 1998;17:2133-2146.

37. Wiens BL, Dmitrienko A. The fallback procedure for evaluating a single family of hypotheses. J Biopharm Stat. 2005;15:929-942.

38. Davis LJ. Exact tests for $2 \times 2$ contingency tables. Am Stat. 1986;40:139-140.

39. Mehrotra DV, Chan ISF, Berger RL. A cautionary note on exact unconditional inference for a difference between two independent binomial proportions. Biometrics. 2003;59:441-.

40. Dexter F, Ledolter J, Hindman BJ. Bernoulli cumulative sum (CUSUM) control charts for monitoring of anesthesiologists' performance in supervising anesthesia residents and nurse anesthetists. Anesth Analg. 2014;119:679.

41. Koff MD, Loftus RW, Burchman CC, Schwartzman JD, Read ME, Henry ES, Beach ML. Reduction in intraoperative bacterial contamination of peripheral intravenous tubing through the use of a novel device. Anesthesiology. 2009;110:978

42. Loftus RW, Muffly MK, Brown JR, Beach ML, Koff MD, Corwin HL, Surgenor SD, Kirkland KB, Yeager MP. Hand contamination of anesthesia providers is an importan risk factor for intraoperative bacterial transmission. Anesth Analg. 2011;112:98.

43. Loftus RW, Brindeiro BS, Kispert DP, Patel HM, Koff MD, Jensen JT, Dodds TM, Yeager MP, Ruoff KL, Gallagher JD, Beach ML, Brown JR. Reduction in intraoperative bacterial contamination of peripheral intravenous tubing through the use of a passive catheter care system. Anesth Analg. 2012;115:1315.

44. Koff MD, Brown JR, Marshall EJ, O'Malley AJ, Jensen JT, Heard SO, Longtine K, O'Neill M, Longtine J, Houston D, Robison C, Moulton E, Patel HM, Loftus RW. Frequency of hand decontamination of intraoperative providers and reduction of postoperative healthcare-associated infections: A randomized clinical trial of a novel hand hygiene system. Infect Control Hosp Epidemiol. 2016;37:888.

45. Haley RW, Culver DH, Morgan WM, White JW, Emori TG, Hooton TM. Identifying patients at high risk of surgical wound infection: a simple multivariate index of patient susceptibility and wound contamination. Am J Epidemiol. 1985;121:206.

46. Gaynes RP, Culver DH, Horan TC, Edwards JR, Richards C, Tolson JS. Surgical site infection (SSI) rates in the United States, 1992-1998: the National Nosocomial Infections Surveillance System basic SSI risk index. Clin Infect Dis. 2001;33(Suppl 2):69-77.

47. Mu Y, Edwards JR, Horan TC, Berrios-Torres SI, Fridkin SK. Improving risk-adjusted measures of surgical site infection for the national healthcare safety network. Infect Control Hosp Epidemiol. 2011;32:970.

48. Dexter F, Wachtel RE, Epstein RH. Decreasing the hours that anesthesiologist and nurse anesthetists work late by making decisions to reduce the hours of over-utilized operating room time. Anesth Analg. 2016;122:831-842.

49. Masursky D, Dexter F, Isaacson SA, Nussmeier NA. Surgeons' and anesthesiologists' perceptions of turnover times. Anesth Analg. 2011;112:440-444.

50. Dexter F, Jarvie C, Epstein RH. At most hospitals in the State of Iowa, most surgeons' daily lists of elective cases include only 1 or 2 cases: individual surgeons' percentage operating room utilization is a consistently unreliable metric. $J$ Clin Anesth. 2017;42:88-92

51. Dexter F, Epstein RH, Podgorski EM, Pearson ACS. Appropriate operating room time allocations and half-day block time for low caseload proceduralists, including anesthesiologist pain medicine physicians in the State of Florida. J Clin Anesth. 2020;64:109817.

52. Dowell SF, Simmerman JM, Erdman DD, Wu JS, Chaovavanich A, Javadi M, Yang JY, Anderson LJ, Tong S, Ho MS. Severe acute respiratory syndrome coronavirus on hospital surfaces. Clin Infect Dis. 2004;39:652-657.

53. Otter JA, Donskey C, Yezli S, Douthwaite S, Goldenberg SD, Weber DJ. Transmission of SARS and MERS coronaviruses and influenza virus in healthcare settings: the possible role of dry surface contamination. J Hosp Infect. 2016;92:235-250.

54. Chin AWH, Chu JTS, Perera MRA, Hui KPY, Yen HL, Chan MCW, Peiris M. Stability of SARSCoV-2 in different environmental conditions. Lancet. 2020. https://doi.org/10. 1016/S2666-5247(20)30003-3.

55. van Doremalen N, Bushmaker T, Morris DH, Holbrook MG, Gamble A, Williamson BN, Tamin A, Harcourt JL, Thornburg NJ, Gerber SI, Lloyd-Smith JO. Aerosol and surface stability of SARS-CoV-2 as compared with SARS-CoV-1. N Engl J Med. 2020;382:1564-;1567.

56. Wu S, Wang Y, Jin X, Tian J, Liu J, Mao Y. Environmental contamination by SARSCoV-2 in a designated hospital for coronavirus disease 2019. Am J Infect Control. 2020. https://doi.org/10.1016/j.ajic.2020.05.003.

57. Cadnum JL, Li DF, Redmond SN, John AR, Pearlmutter B, Donskey CJ. Effectiveness of ultraviolet-C light and a high-level disinfection cabinet for decontamination of N95 respirators. Pathog Immun. 2020;5:52-67.

[58]. Liao L, Xiao W, Zhao M, Yu X, Wang H, Wang Q, Chu S, Cui Y. Can N95 respirators be reused after disinfection? How many times? ACS Nano. 2020. https://doi.org/ 10.1021/acsnano.0c03597 ePub DOI:.

59. Cheng VCC, Wong SC, Kwan GSW, Hui WT, Yuen KY. Disinfection of N95 respirators by ionized hydrogen peroxide during pandemic coronavirus disease 2019 (COVID19) due to SARS-CoV-2. J Hosp Infect. 2020. https://doi.org/10.1016/j.jhin.2020.04. 003 ePub DOI:. 